\title{
ENSAIOS
}

\section{POLÍTICA, ASSOCIATIVISMO E ESPORTE UNIVERSITÁRIO NA DÉCADA DE 1930}

POLITICS, ASSOCIATIONS, AND COLLEGE SPORTS IN THE 1930s C己

POLÍTICA, ASOCIATIVISMO Y DEPORTE UNIVERSITARIO EN LOS

AÑOS 1930 C P

doi' https://doi.org/10.22456/1982-8918.100596

Vitor Lucas de Faria Pessoa* < vitorlfpessoa@hotmail.com>

Cleber Dias* <cleberdiasufmg@gmail.com>

*Universidade Federal de Minas Gerais. Belo Horizonte, MG, Brasil.

Resumo: O objetivo deste ensaio é analisar as relações que se estabeleceram entre o Estado e as associações esportivas universitárias durante a década de 1930 até o início da década seguinte. Para tanto, utilizamos jornais do acervo da Biblioteca Nacional do Rio de Janeiro, assim como bibliografia especializada que trata sobre o tema. Nesse período, os esportes foram uma instância institucional relevante no agenciamento de relações entre o Estado e estudantes universitários. Além disso, a natureza dessas relações acabou por determinar o modo como os esportes se desenvolveram nas universidades brasileiras daí em diante, modelando uma arquitetura institucional que de certo modo sobrevive até os dias de hoje.

Palavras chave: Esportes. História. Universidades.

Recebido em: 19-02-2020 Aprovado em: 08-07-2020 Publicado em: 21-08-2020

\section{(c) (i) ()}

Este é um artigo publicado sob a licença Creative Commons atribuição Não Comercial 4.0 (CC BY-NC 4.0).

eISSN: 1982-8918 


\section{INTRODUÇÃO}

A sistematização do esporte universitário no Brasil se deu a partir do início da década de 1930, quando surgiram as primeiras federações esportivas universitárias. De início, associações estudantis estiveram entre os principais agentes para o desenvolvimento de iniciativas esportivas entre universitários brasileiros. As primeiras equipes esportivas universitárias surgiram no interior de centros e grêmios acadêmicos. Os esportes, além disso, estiveram na pauta de discussões, reuniões e assembleias estudantis ao menos desde o início da década de 1930, de modo que esforços para estruturação nacional de organizações universitárias que aconteciam nessa época, na esteira da própria criação das universidades brasileiras, tiveram, desde o início, os esportes como objeto de preocupações (PESSOA; DIAS, 2019).

Mais que debater ou promover ocasiões para a prática esportiva, associações estudantis também cumpriam um papel político relevante. Com efeito, ao longo de toda a década de 1930, houve proximidade crescente entre associações universitárias e outras instituições políticas, como partidos e governos. Diante desse cenário, o objetivo deste artigo é analisar as relações que se estabeleceram entre o Estado e as associações esportivas universitárias durante a década de 1930 até o início da década seguinte. Nesse período, as associações esportivas foram instâncias relevantes no agenciamento de relações entre o Estado e estudantes universitários. Além disso, a natureza dessas relações acabou por determinar o modo como os esportes se desenvolveram nas universidades brasileiras daí em diante. Nesse sentido, a década de 1930 aparece como um período especialmente relevante, na medida em que marcou, por um lado, uma inflexão no modo como associações esportivas universitárias vinham se organizando até aí, ao mesmo tempo em que, por outro, modulou uma arquitetura institucional que de certo modo sobrevive até os dias de hoje.

O início do envolvimento governamental regular e sistemático com esportes no Brasil usualmente é datado a partir da década de 1930. Iniciativas governamentais dedicadas aos esportes havia desde antes, mas tinham um caráter menos regular e sistemático (SANTOS; MELO, 2012). A partir de 1930, no entanto, essas iniciativas desenvolveram regularidades maiores e mais explícitas, geralmente utilizando essas práticas como instrumento para propaganda ideológica e para ampliação de estratégias de preparação física ou militar (sobretudo de jovens). Tudo isso tem sido repetidamente apontado pela bibliografia especializada (COUTO, 2014; DRUMOND, 2014; HORTA, 2012; LINHALES, 1996; STAREPRAVO, et al., 2010). Todavia, há outro aspecto que tem sido pouco enfatizado: a utilização dos esportes como meios através dos quais agentes do governo tentavam dissipar tensões e cooptar a cooperação política de grupos que Ihe faziam oposição. Este ensaio, através de um estudo sobre a relação entre as associações universitárias dedicadas aos esportes e o Estado na década de 1930, analisa, justamente, essa dimensão, concentrando-se, mais especificamente, no modo como o Estado tentou utilizar e se apropriar politicamente de práticas esportivas não apenas para propaganda, eugenia e preparação militar. Segundo nosso argumento, além de propaganda e recurso para eugenia ou preparação física e militar, nessa época, os esportes também foram 
estratégia de cooptação e desarticulação política de grupos que se opunham ao governo. Além de sublinhar este aspecto, outro argumento geral do ensaio é o de que as consequências históricas desse processo se fazem notar até os dias de hoje.

\section{ESPORTE UNIVERSITÁRIO E POLÍTICA}

O processo político que culminou com o fim da Primeira República e a ascensão da chamada Revolução de 1930, que levou, por sua vez, a um golpe de Estado que instalou uma ditadura em 1937 (Estado Novo), não se realizou sem que houvesse oposições. Entre os grupos de oposição mais ativos e politicamente representativos estiveram os estudantes universitários (DULLES, 1984; LOPES, 2004).

Como parte da estratégia para aplacar esses conflitos, o Governo Provisório, e depois ainda mais o Estado Novo, buscou cooptar politicamente ou enfraquecer por meio da repressão ou da desarticulação política grupos que não o apoiavam ou lhe faziam oposição. Considerando o ativo papel político que estudantes universitários desempenhavam nesse momento, esportes praticados em universidades logo foram utilizados pelo governo como mais uma ferramenta para essas disputas políticas.

O esporte universitário foi mesmo um fator importante para a atuação política de diferentes grupos nessa época. De um lado, associações como sindicatos ou centros estudantis utilizavam-no como recurso para mobilização e incentivo à participação política mais geral (BATALHA, 2004; PESSOA; DIAS, 2019). Ao contrário de certo lugar comum que destaca os esportes como um espaço social de controle e alienação, associações culturais e recreativas, incluindo aí as esportivas, ao longo de toda a década de 1930 serviram como importantes locais para mobilização, articulação e expressão de interesses políticos (PENNA-FRANCA, 2018; PEREIRA, 2017; 2013). De outro lado, instâncias governamentais utilizavam os esportes como parte dos seus esforços para propagandear ideologias e construir um sentimento de coesão entre jovens, que nessa época tinha nos estudantes um alvo privilegiado (PARADA, 2009).

Em conformidade a essas prerrogativas governamentais para os esportes, desde os meados da década de 1930, quando se inicia o processo de criação das federações esportivas universitárias, o Estado já participava ativamente de tentativas de forjar uma retórica que destacasse a união entre os estudantes do país. Deliberadamente, pois, líderes do governo ofereciam apoio financeiro a entidades acadêmicas esportivas, ao mesmo tempo em que disseminavam, por meio da imprensa submetida à censura, noções de que os universitários faziam parte de uma mesma família e uma mesma pátria, onde não seria adequado, portanto, quaisquer formas de divergências e conflitos (PESSOA; DIAS, 2019).

Durante os últimos anos da década de 1930 e princípios da década de 1940, competições esportivas foram cada vez mais usualmente realizadas com apoio financeiro do Estado (PESSOA; DIAS, 2019). Tais apoios faziam parte de um "programa de aproximação da juventude universitária", conforme palavras publicadas por um jornal do Rio de Janeiro, em notícia sobre um campeonato de basquete entre todas as escolas superiores do Distrito Federal, realizado na Universidade do Brasil 
(atual Universidade Federal do Rio de Janeiro) (INICIADO..., 1940). Desse momento em diante, como expressão de um programa político deliberadamente articulado, alguns estudantes identificados com o ideário estado-novista ganharam protagonismo na direção de associações universitárias, onde sustentariam o entendimento de que o propósito de reuniões entre estudantes deveria ser o de promover "cooperação maior de todos os estudantes do Brasil, visando unificar o pensamento acadêmico" - tal como fez Marcelo Coimbra, presidente do Centro Acadêmico Castro Alves, da Universidade de Minas Gerais em entrevista ao jornal Diário de Notícias, do Rio de Janeiro, por ocasião do IV Congresso Nacional dos Estudantes, realizado naquela cidade (INSTALA-SE..., 1940). Grosso modo, a partir de meados da década de 1930, aproximadamente, a justificativa para a realização de eventos esportivos universitários logo reproduziria essa mesma estrutura discursiva, qual seja, de que esportes serviam ao congraçamento da mocidade, donde não caberia conflitos, divergências ou dissidências.

Políticos tomariam parte ativa nesse processo, participando pessoalmente em cerimônias desses eventos. Durante a II Olimpíada Universitária Brasileira, por exemplo, realizada em São Paulo, em 1939, o próprio Getúlio Vargas, bem como Adhemar de Barros, o interventor por ele nomeado para o governo de São Paulo, estiveram na cerimônia de abertura da competição, "demonstrando o alto interesse que possuem pela elevação do esporte universitário", conforme noticiou o jornal Correio Paulistano (COLLEGAS..., 1939). Mais que isso, no ano seguinte, durante uma nova Olimpíada Universitária, realizada novamente em São Paulo, Getúlio Vargas foi nomeado presidente honorário da Confederação Universitária Brasileira de Esportes (CUBE) - uma associação criada em 1939 com o propósito de coordenar todas as federações esportivas universitárias que atuavam nos Estados (ver Figura 1).

Figura 1 - Entrega de título de presidente honorário da CUBE a Getúlio Vargas.

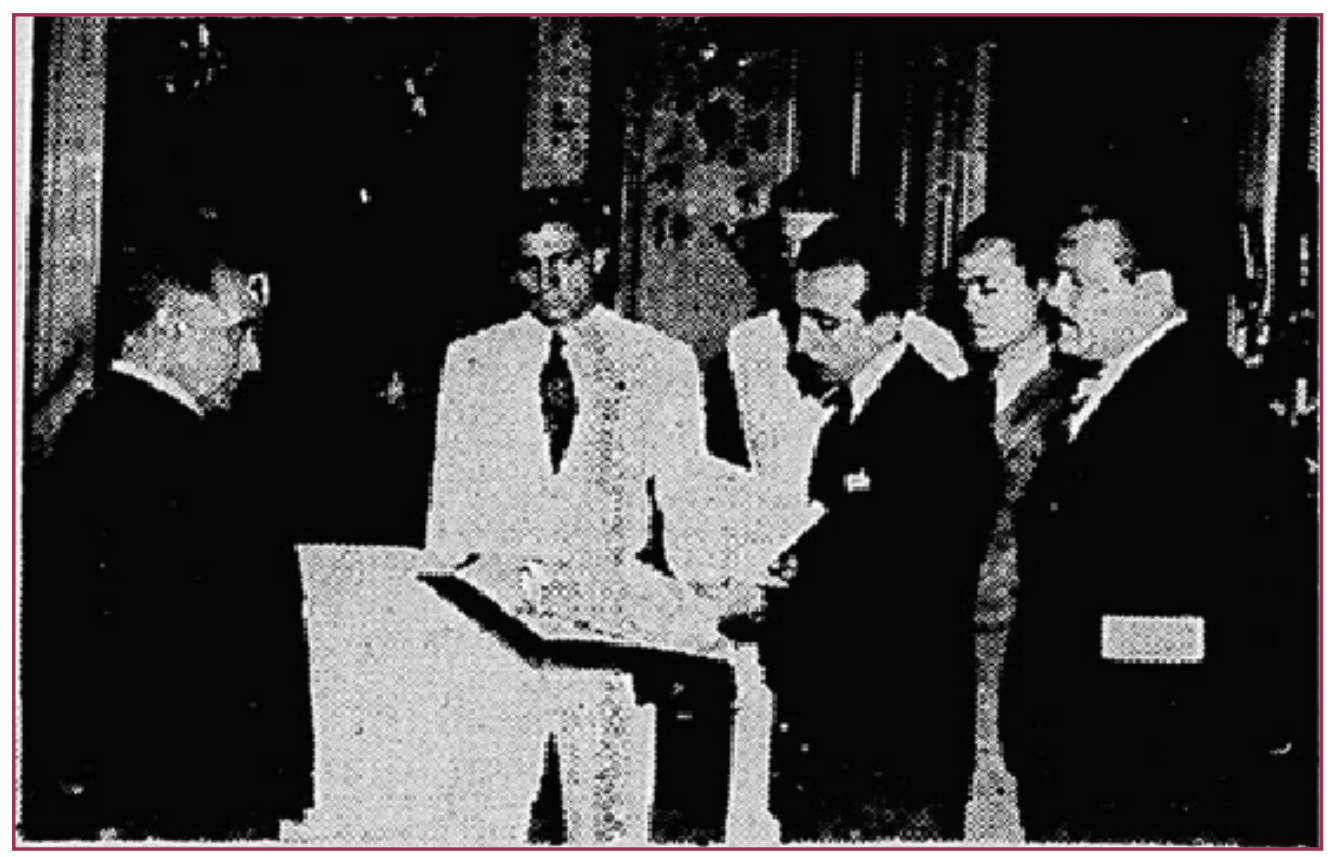

Fonte: Os estudantes Brasileiros ao Presidente Getúlio Vargas. A Batalha, Rio de Janeiro, 16 jul. 1940, p. 1. 
Assim, a prática de esportes no ambiente das universidades durante a década de 1930 não era destituída de importância política. Ao contrário, o envolvimento com os esportes conferia certo capital simbólico aos acadêmicos, dando-lhes legitimidade para a atuação política. A conquista de posições políticas proeminentes na direção de organizações estudantis também poderia projetar indivíduos entre instituições esportivas, o que, por sua vez, poderia impulsionar sua influência entre organizações políticas mais gerais, reforçando uma cadeia de relações entre universidades, esportes e política. Em 1935, por exemplo, a eleição de Roberto Whately para a presidência do Centro Acadêmico XI de Agosto, da Faculdade de Direito da Universidade de São Paulo, é grandemente atribuída à sua condição de famoso atleta de tênis (ver DULLES, 1984, p. 81). Pouco antes do início das eleições, o jornal Correio Paulistano publicou uma entrevista com os estudantes que disputavam o pleito. A descrição do perfil de Whately enfatizava sua popularidade obtida graças a conquistas nos campos de esportes. Segundo se lê:

\begin{abstract}
Whately goza de grande popularidade entre os acadêmicos de Direito mercê dos seus dotes de coração e espírito e também por ser um esportista [ilegível], já tendo defendido a Faculdade em vários encontros tenísticos. Nessa modalidade esportiva Whately conquistou também nítidos triunfos para São Paulo, tendo, em 1933, conquistado o campeonato brasileiro de tênis, após belíssimos encontros. Encontramos Roberto Whately disputando, na sede do Centro [XI de Agosto], um dos encontros do campeonato de xadrez entre acadêmicos [depois de um lance magistral, colocando seu adversário fora de combate com um "xeque-mate"] (A POLÍTICA..., 1935, p. 12).
\end{abstract}

Nessa época, vários setores ligados às associações estudantis universitárias faziam oposição declarada ao governo de Getúlio Vargas. Estudantes ligados à Faculdade de Direito do Largo de São Francisco, em particular, protagonizaram várias manifestações contrárias a Getúlio Vargas. Era do interesse do governo, portanto, tentar ampliar seu raio de influência sobre associações estudantis como uma forma de mitigar parte dessa oposição. A eleição de uma figura como Roberto Whately para a presidência do Centro Acadêmico da Faculdade de Direito da Universidade de São Paulo, no entanto, que se opunha abertamente ao governo de Vargas, dificultava tais ambições.

Se o governo enfrentava dificuldades ou sofria derrotas políticas nas disputas pelo controle das associações estudantis, a ampliação do seu raio de influência sobre o universo esportivo universitário nos anos seguintes logo se apresentaria como uma alternativa viável aos seus propósitos de enfraquecer setores do movimento estudantil que lhe faziam oposição. Como se sabe, depois da promulgação do Estado Novo, em 1937, esforços para a centralização da vida política nos interstícios das estruturas institucionais do Estado se intensificaram, o que também afetou associações esportivas universitárias. Daí em diante, o Estado se tornou não apenas um apoiador eventual de iniciativas esportivas de estudantes, como tinha sido até então, mas, sim, um agente proativo na formulação de diretrizes ideológicas e organizacionais que deveriam orientar a atuação de associações estudantis (PESSOA; DIAS, 2019).

Paulatinamente, o apoio, sobretudo financeiro, oferecido pelo governo a eventos esportivos universitários organizados por grupos de estudantes com mais 
afinidades com as ideologias e os interesses políticos governamentais imediatos fortaleceu esses grupos, a ponto de eles estarem em condições de assumirem o controle de algumas das principais associações esportivas universitárias do período, como eram a Federação Universitária Paulista de Esportes (FUPE) e a Confederação Universitária Brasileira de Esportes (CUBE), responsáveis pela organização dos maiores e mais representativos campeonatos esportivos universitários daquele período. Na verdade, fora o apoio mesmo do governo um dos principais elementos a permitir que tais associações (sediadas em São Paulo) adquirissem tamanha relevância e capacidade organizacional. Grupos alheios ou excluídos desses jogos de interesse seguiram operando de maneira mais precária, com recursos e capacidade visivelmente menores. A Federação Atlética de Estudantes, por exemplo, associação esportiva fundada por universitários do Rio de Janeiro, que não teve ou não quis ter entre seus diretores estudantes com afinidades com os interesses do governo, viveu desde a sua fundação, em 1933, certa instabilidade institucional, além de ter sempre aparentado possuir poucos recursos materiais para suas iniciativas. A Federação Atlética de Estudantes se mostrou repetidamente incapaz de organizar campeonatos esportivos que tivessem abrangência nacional, com envolvimento de estudantes-esportistas de vários estados, que eram então sempre realizados em São Paulo, justamente pelas associações dirigidas por grupos sintonizados com os interesses do governo. Assim, a proximidade política com o governo parecia ser um fator decisivo para ampliar ou obstruir o acesso a recursos financeiros do Estado, determinando, dessa forma, o destino de sucesso ou de fracasso das associações esportivas universitárias (PESSOA; DIAS, 2019).

No âmbito das associações esportivas universitárias, o ponto culminante deste processo foi a criação da Confederação Brasileira de Desportos Universitários (CBDU), que substituiu e centralizou, em 1941, a ação de outras organizações criadas antes pelos próprios estudantes, como a Confederação Universitária Brasileira de Esportes (CUBE), imprimindo-lhes um novo caráter, grandemente subordinada ao governo. Na prática, a recém-criada CBDU atuava como uma espécie de sucursal do Ministério da Educação, de onde vinham orientações e diretrizes (PESSOA; DIAS, 2019).

José Gomes Talarico, bastante ativo no cenário político, universitário e esportivo de São Paulo desde meados da década de 1930, atuou como um dos principais articuladores do processo que levou à criação da CBDU, isto é, da fundação da entidade que suprimiria a autonomia das associações esportivas universitárias existentes até ali, subordinando-Ihes ao controle centralizador exercido pelo Estado. Entre 1937 e 1941, Talarico, que era próximo de Getúlio Vargas e de Gustavo Capanema (Ministro da Educação de Vargas), ocupou posições-chave no associativismo estudantil e esportivo de São Paulo, além de ter gozado de relativo protagonismo em esferas da política partidária da cidade: foi diretor do Centro Acadêmico da Faculdade de Medicina da Universidade de São Paulo, presidente da Federação Universitária Paulista de Esportes (FUPE), membro da diretoria da Confederação Universitária Brasileira de Esportes (CUBE), que se tornaria depois a Confederação Brasileira de Desportos Universitários, ou CBDU) e filiado ao Partido Republicano Paulista, onde desempenhou papéis de relativo destaque. Não por 
acaso, foi ele quem entregou o diploma de presidente honorário da CUBE a Getúlio Vargas, durante Olimpíada Universitária realizada em São Paulo, em 1940 (ver Figura 1). A proximidade e a afinidade de Talarico com o primeiro escalão do Estado Novo provavelmente facilitaram que as diretrizes do governo fossem assimiladas pelas instituições esportivas universitárias, especialmente aquelas com as quais ele estava envolvido, cujo ponto culminante, como dissemos, foi a criação da CBDU em 1941(PESSOA; DIAS, 2019).

Todavia, os esforços dos aparelhos burocráticos do Estado para controlar as instituições esportivas universitárias não foram consensuais ou pacíficos, embora se possa dizer que foram, ao final, bem-sucedidos. O desenrolar do processo foi perpassado por oposições e divergências. Em setembro de 1941, por exemplo, mesmo mês em que foi criada a CBDU, em substituição à mais antiga CUBE, alunos da Universidade de São Paulo propuseram a concessão de um título de doutor honoris causa a Getúlio Vargas. A proposta, porém, gerou uma crise na Faculdade de Direito, onde vários estudantes se mostraram contrários à medida. Por outro lado, José Gomes Talarico, a essa altura já bastante influente nos meios universitários, saiu em defesa da medida, mobilizando duas organizações esportivas dirigidas por ele em favor da proposta: a Confederação Brasileira de Desportos Universitários e a Federação Universitária Paulista de Esportes (DULLES, 1984, p. 174). O apoio de Talarico e das instituições esportivas universitárias à concessão do título de doutor honoris causa a Vargas foi criticado por outros setores estudantis, que convocaram então uma assembleia extraordinária para discutir o assunto. Como resoluções, propuseram-se greve de um dia e a proibição da presença de Talarico nas dependências da Faculdade de Direito (DULLES, 1984, p. 166-167). Houve ainda depredações à sede da CBDU, que terminaram em brigas entre os apoiadores e os críticos à concessão do título de doutor honoris causa a Vargas (DULLES, 1984, p. 182).

Apesar das oposições e divergências, no entanto, preponderaram as posições e capacidade de influência daqueles com maior afinidade com as ideologias e os interesses políticos do governo. Prova-o a própria fundação da CBDU, anunciada como "oficialização dos esportes universitários", isto é, como a passagem do controle dessas associações estudantis para entidades e instituições "oficiais" (leia-se, governamentais). Depois disso, e até 1945 pelo menos, quando termina a ditadura estado-novista, O Estado exercia efetivo controle financeiro e organizacional sobre os rumos e destinos do esporte universitário no Brasil. A criação da CBDU, que se tornara então uma organização "oficial", passava a monopolizar a coordenação de atividades esportivas entre universitários no Brasil. Concepções divergentes daquelas propugnadas pelo Estado a respeito dos modos de organização de associações esportivas universitárias não encontraram canais de expressão política. Propostas para profissionalização dos esportes universitários, por exemplo, que circularam entre setores estudantis envolvidos com a direção de associações esportivas universitárias, não tiveram condições de possibilidade para serem apresentadas, apreciadas e eventualmente implementadas no âmbito dessas instituições, na medida mesmo em que tais ideais se opunham à concepção geral defendida pelo governo, que as controlava e insistia nas vantagens do amadorismo como única forma de assegurar 
o caráter educativo de práticas esportivas. Tais impossibilidades eram especialmente cerceadoras pela proibição de outras instituições concorrentes, onde concepções alternativas poderiam ter sido postas em prática.

\section{CONSIDERAÇÕES FINAIS}

A apropriação das associações esportivas universitárias pelo Estado não ocorreu de forma abrupta, tampouco os estudantes estiveram alheios a esse processo. Ao contrário, esse processo, que se desdobrou lenta e progressivamente por um período aproximado de dez anos (1930-1940), contou ainda com ativa participação de lideranças estudantis, que em alguma medida obtinham benefícios diretos ou indiretos. Primeiro, porque a "oficialização do esporte universitário" garantia recursos financeiros para algumas iniciativas das organizações dedicadas a promover campeonatos esportivos entre estudantes, especialmente aquelas dirigidas por estudantes alinhados ideológica e politicamente com o governo. Segundo, mais que isso, porque lideranças estudantis envolvidas e comprometidas com esse processo gozaram de proximidade com altos escalões do governo, donde podiam extrair vantagens pessoais. Não por acaso, críticos dos líderes estudantis mais ativamente envolvidos com o processo de "oficialização dos esportes universitários" acusavamIhes de praticarem a "cavação", isto é, conforme vocabulário da época, esforços deliberados para cavar oportunidades para si próprio. José Gomes Talarico, um dos principais artífices dessa "oficialização dos esportes universitários", tornou-se, logo após a criação da CBDU, inspetor do Ministério do Trabalho do governo de Vargas.

Além disso, devemos ainda nos perguntar, de forma factual e contrafactual, sobre as consequências históricas desse processo para o esporte universitário no Brasil. Tivesse adotado um modelo profissional, por exemplo, como aconteceu nos Estados Unidos e como cogitavam alguns setores estudantis, o modelo organizacional dos esportes universitários adotado no Brasil teria sido diferente?

É impossível responder a essa pergunta, pois especular sobre o que poderia ter sido caso o que aconteceu não tivesse acontecido é apenas um exercício (útil) de imaginação sociológica. No entanto, consequências do processo de utilização dos esportes como ferramenta política por agentes do Estado podem ser apontadas. Uma das principais é a despolitização das associações esportivas universitárias. Aqui, despolitização deve ser entendida como a erosão da capacidade de autoorganização e agenciamento de seus próprios interesses coletivos. Ao invés disso, depois da "oficialização dos esportes universitários" através da criação da CBDU seguiu-se uma dependência crônica das associações esportivas universitárias do Estado, especialmente no âmbito econômico. A dependência econômica tinha como contrapartida obediência a diretrizes organizacionais e políticas emanadas do governo. Além disso, elementos políticos mais gerais que usualmente perpassavam iniciativas das associações estudantis para os esportes, tais como esforços para utilização de campeonatos como estratégia de mobilização ou como ocasião para discussão de outras reivindicações, praticamente deixaram de existir. Sintoma da despolitização dos esportes universitários está na perda de expressão política dos líderes das associações esportivas estudantis depois desse processo de 
"oficialização". Depois disso, estudantes envolvidos com a direção de associações esportivas universitárias não tiveram mais protagonismo político comparável ao da geração que lhes antecedeu - bastante atuantes politicamente ao longo da década de 1930. Nesse sentido, a atribuição de um caráter alienado aos esportes, em geral, e aos esportes universitários, em particular, é de certo modo resultado de uma leitura retrospectiva desses fenômenos, pois até meados da década de 1930, precisamente quando se intensifica o empenho governamental em se apropriar e instrumentalizar, essas instâncias eram espaços sociais bastante politizados. Finalmente, a persistente reinvindicação de apoio governamental a iniciativas esportivas organizadas por associações estudantis, que segue algo bastante vivo até os dias de hoje, quando vista sob as lentes dessa história, parece tão somente a reprodução de habitus que corroem a autonomia política e organizacional dessas entidades, criando ou mantendo status de dependência e subordinação.

\section{REFERÊNCIAS}

A POLÍTICA das Arcadas em plena effervescencía. Correio Paulistano, São Paulo, 4 set. 1935, p. 12.

BATALHA, Claudio Henrique de Moraes. Cultura associativa no Rio de Janeiro da Primeira República. In: BATALHA, Claudio Henrique de Moraes; SILVA, Fernando Teixeira da;

FORTES, Alexandre (orgs.). Culturas de classe: identidade e diversidade na formação do operariado. Campinas: Editora da UNICAMP, 2004. p. 95-119.

COLLEGAS de todo Brasil, S. Paulo vos espera de braços abertos. Correio Paulistano, São Paulo, out. 1939, p. 8.

COUTO, Euclides de Freitas. Da ditadura à ditadura: uma história política do futebol brasileiro (1930-1978). Niterói: Editora da UFF, 2014.

DRUMOND, Maurício. Estado Novo e esporte: a política e o esporte em Getúlio Vargas e Oliveira Salazar (1930-1945). Rio de Janeiro: 7 Letras, 2014.

DULLES, John Watson Foster. A Faculdade de Direito de São Paulo e a resistência antiVargas: 1938-1945. Rio de Janeiro; São Paulo: Nova Fronteira; Editora da Universidade de São Paulo, 1984.

HORTA, José Silvério Baía. O hino, o sermão e a ordem do dia: regime autoritário e a educação no Brasil (1930-1945). 2. ed. Campinas: Autores Associados, 2012.

INICIADO o Campeonato de Bola ao Cesto. Diário de Notícias, Rio de Janeiro, 18 out. 1940, p. 6.

INSTALA-SE, hoje, o IV Congresso Nacional de Estudantes. Diário de Notícias, Rio de Janeiro, 19 jul. 1940, p. 3.

LINHALES, Meily Assbú. A trajetória política do esporte no Brasil: interesses envolvidos, setores excluídos. 1996. 242f. Dissertação (Mestrado em Ciência Política) - Universidade Federal de Minas Gerais, Belo Horizonte, 1996.

LOPES, Marta Aparecida Rodrigues. O movimento estudantil brasileiro e o ensino superior no período de 1937 a 1964. 2004. 109f. Dissertação (Programa de Pós Graduação em Educação) - Universidade São Francisco. Bragança Paulista, 2004. 
OS ESTUDANTES Brasileiros ao Presidente Getúlio Vargas. A Batalha, Rio de Janeiro, 16 de julho de 1940, p. 1.

PARADA, Maurício. Educando corpos e criando a nação: cerimônias cívicas e práticas disciplinares no Estado Novo. Rio de Janeiro: Apicuri, 2009

PENNA-FRANCA, Luciana. Teatro amador no Rio de Janeiro: associativismo dramático na construção da cidadania. Topoi, v. 19, n. 39, p. 95-121, 2018.

PEREIRA, Leonardo Affonso de Miranda. A dança da política: trabalhadores, associativismo recreativo e eleições no Rio de Janeiro da Primeira República. Revista Brasileira de História, v. 37, p. 63-88, 2017.

PEREIRA, Leonardo Affonso de Miranda. Os Anjos da Meia-Noite: trabalhadores, lazer e direitos no Rio de Janeiro da Primeira República. Tempo, v. 19, n. 35, p. 97-116, 2013.

PESSOA, Vitor Lucas de Faria; DIAS, Cleber. História do esporte universitário no Brasil (1933-1941). Movimento, v. 25, e25016, 2019.

SANTOS, João Manuel Casquinha Malaia; MELO, Victor Andrade de (orgs.). 1922: comemorações esportivas do centenário. Rio de Janeiro: 7 Letras; 2012.

STAREPRAVO, Fernando Augusto et al. Esporte universitário brasileiro: uma leitura a partir de suas relações com o Estado. Revista Brasileira de Ciências do Esporte, v. 31, n. 3, p. 131-148, 2010. 
Abstract: This paper analyzes the relationships established between the State and college sports associations from the 1930s to the early 1940s. We use newspapers from the National Library in Rio de Janeiro as well as specialized bibliography on the topic. During that period, sports were a relevant institutional sphere in the assemblage of relations between the State and college students. Moreover, the nature of these relationships ultimately determined the way sports developed at Brazilian colleges from then on, shaping an institutional architecture that somehow survives to this day.

Keywords: Sports. History. Universities.

Resumen: El objetivo de este trabajo es analizar las relaciones que se establecieron entre el Estado y las asociaciones deportivas universitarias desde la década de 1930 hasta principios de la década siguiente. Para este fin, usamos periódicos de la Colección de la Biblioteca Nacional de Río de Janeiro, así como bibliografía especializada que aborda el tema de alguna manera. Durante este período, el deporte fue una instancia institucional relevante en la agencia de relaciones entre el estado y los estudiantes universitarios. Además, la naturaleza de estas relaciones determinó en última instancia la forma en que los deportes se desarrollaron en las universidades brasileñas a partir de entonces, configurando una arquitectura institucional que de alguna manera sobrevive hasta nuestros días.

Palabras clave: Deportes. Historia. Universidades. 


\section{LICENÇA DE USO}

Este é um artigo publicado em acesso aberto (Open Access) sob a licença Creative Commons atribuição Não Comercial 4.0 (CC BY-NC 4.0), que permite uso, distribuição e reprodução em qualquer meio, desde que o trabalho original seja corretamente citado, com a restrição que impede o uso para fins comerciais. Mais informações em: http://creativecommons.org/licenses/by-nc/4.0

\section{CONFLITO DE INTERESSES}

Os autores declararam que não há conflito de interesses neste trabalho.

\section{CONTRIBUIÇÕES AUTORAIS}

Vitor Lucas de Faria Pessoa: Coleta de dados, revisão bibliográfica, análise dos dados e escrita

Cleber Dias: Revisão bibliográfica, análise dos dados, escrita, revisão do texto

\section{FINANCIAMENTO}

O presente trabalho foi realizado com apoio da Coordenação de Aperfeiçoamento de Pessoal de Nível Superior - Brasil (CAPES) - Código de Financiamento 001. This study was financed in part by the Coordenação de Aperfeiçoamento de Pessoal de Nível Superior - Brasil (CAPES) - Finance e Fundação de Amparo à Pesquisa do Estado de Minas Gerais (FAPEMIG).

\section{DECLARAÇÃO/COMITÊ DE ÉTICA EM PESQUISA}

Não se aplica.

\section{COMO REFERENCIAR}

PESSOA, Vitor Lucas de Faria; DIAS, Cleber. Política, associativismo e esporte universitário na década de 1930. Movimento, v. 26, e26066, 2020. Disponível em: https://seer.ufrgs.br/Movimento/article/view/100596. Acesso em: 21 ago. 2020. DOI: https://doi.org/10.22456/1982-8918.100596

\section{RESPONSÁVEIS EDITORIAIS}

Alex Branco Fraga*, Elisandro Schultz Wittizorecki*, Ivone Job*, Mauro Myskiw*, Raquel da Silveira*

*Universidade Federal do Rio Grande do Sul, Escola de Educação Física, Fisioterapia e Dança, Porto Alegre, RS, Brasil 